\title{
AI customer service: Task complexity, problem-solving ability, and usage intention
}

\author{
Yingzi Xu ${ }^{\mathrm{a}}$, Chih-Hui Shieh ${ }^{\mathrm{b}}$, Patrick van Esch ${ }^{\mathrm{a}}$, I-Ling Ling ${ }^{\mathrm{c}, 1, *}$ \\ a AUT Business School, Department of Marketing, Auckland University of Technology, New Zealand \\ ${ }^{\mathrm{b}}$ Department of Marketing and Distribution Management, National Kaohsiung University of Science and Technology, Taiwan \\ ${ }^{\mathrm{c}}$ Centre for General Education, Kaohsiung Medical University, Taiwan
}

\section{A R T I C L E I N F O}

\section{Article history:}

Received 26 November 2019

Revised 11 March 2020

Accepted 17 March 2020

Available online xxx

\section{Keywords:}

AI customer service

AI definition

Task complexity

Problem-solving ability

Usage intention

\begin{abstract}
A B S T R A C T
Artificial intelligence (AI) in the context of customer service, we define as a technology-enabled system for evaluating real-time service scenarios using data collected from digital and/or physical sources in order to provide personalised recommendations, alternatives, and solutions to customers' enquiries or problems, even very complex ones. We examined, in a banking services context, whether consumers preferred AI or Human online customer service applications using an experimental design across three field-based experiments. The results show that, in the case of low-complexity tasks, consumers considered the problem-solving ability of AI to be greater than that of human customer service and were more likely to use AI while, conversely, for high-complexity tasks, they viewed human customer service as superior and were more likely to use it than AI. Moreover, we found that perceived problem-solving ability mediated the effects of customers' service usage intentions (i.e., their preference for AI vs. Human) with task complexity serving as a boundary condition. Here we discuss our research and the results and conclude by offering practical suggestions for banks seeking to reach customers and engage with them more effectively by leveraging the distinctive features of AI customer service.
\end{abstract}

(c) 2020 The Author(s). Published by Elsevier Ltd on behalf of Australian and New Zealand Marketing Academy. This is an open access article under the CC BY-NC-ND license. (http://creativecommons.org/licenses/by-nc-nd/4.0/)

\section{Background}

Technology is reshaping the nature of service, customers' service experiences, and customers' relationships with service providers (Bitner, 2017; Van Doorn et al., 2017). Currently, the demand for artificial intelligence (AI) in service is being driven by both customers and organisations in search of operational efficiency (Huang and Rust, 2018; Wirtz et al., 2018).

A chatbot, for example, can reduce customer queue and wait times as well labour costs for an organisation (Ostrom et al., 2019; Turel and Connelly, 2013; Xu, 2016). However, AI service robots also affect customers' relationships with service providers with respect to changes in the human touch points along the cus-

\footnotetext{
* Corresponding author.

E-mail addresses: yingzi.xu@aut.ac.nz (Y. Xu), chs102@nkust.edu.tw (C.-H. Shieh), patrick.van.esch@aut.ac.nz (P. van Esch), yiling@kmu.edu.tw (I.-L. Ling).

1 We thank I-Hsuan Li and I-Hsuan Chan who helped the authors to collect the experimental data.
}

tomer journey and perceptions of the social presence of robots (Van Doorn et al., 2017).

For service organisations, the question is not whether to use AI but to what extent and how to maximise its capacity to improve the efficiency and effectiveness of the services that they provide (Huang anad Rust, 2018; Ostrom et al., 2019; Rust, 2019; Wirtz et al., 2018). Currently, AI is being utilised in such service industries as education, finance, health care, retailing, and transportation. More research is required to explore AI as an end-toend service solution rather than simply a component of an organisation's customer service system (Xiao and Kumar, 2019). There is also a need for a deeper understanding of customers' thoughts, feelings, and actions when they are exposed to AI-enabled frontline service interactions (Ostrom et al., 2019).

For this study, we compared customers' reactions to a bank's AI customer service agent (a chatbot) with their reactions to a human customer service employee when using live-chat customer service systems for their inquiries. We also considered the influence of the task complexity of the inquiries on AI usage intention. In the following discussion, we first review the theoretical background on 
Table 1

Definitions of AI.

\begin{tabular}{|c|c|c|}
\hline Source & Definition & Context \\
\hline Dobrev (2005, p. 2) & $\begin{array}{l}\text { "AI will be such a program which in an arbitrary world will } \\
\text { cope not worse than a human" }\end{array}$ & Information programming \\
\hline Dreyfus and Dreyfus (1989, p. 125) & $\begin{array}{l}\text { "autonomous thinking machines that are free of human } \\
\text { control" }\end{array}$ & Human cognitive process \\
\hline Huang and Rust (2018, p. 155) & $\begin{array}{l}\text { "manifested by machines that exhibit aspects of human } \\
\text { intelligence" }\end{array}$ & Services \\
\hline Kaplan and Haenlein (2019, p. 15) & $\begin{array}{l}\text { "a technology system's ability to correctly interpret external } \\
\text { data correctly, learn from such data, and exhibit flexible } \\
\text { adaptation" }\end{array}$ & Business in general \\
\hline Shankar (2018, p. vi) & $\begin{array}{l}\text { "refers to programs, algorithms, systems and machines that } \\
\text { demonstrate intelligence" }\end{array}$ & Retailing \\
\hline Syam and Sharma (2018, p. 136) & "machines mimicking intelligent human behaviour" & Sales \\
\hline Tegmark (2017, p. 39) & "non-biological intelligence" & $\begin{array}{l}\text { Social issues (e.g. crime, } \\
\text { war, justice, jobs, society) }\end{array}$ \\
\hline
\end{tabular}

the use of $\mathrm{AI}$ in customer service and AI problem-solving capability in service contexts. Next, we present our theoretical framework for the mediating effect (i.e., the causal mechanism) of the perceived problem-solving ability of $\mathrm{AI}$ and the moderating effect (i.e., the boundary condition) of task complexity in the context of AI customer service usage intention. We then report three field-based experiments that corroborate our theoretical framework. The paper concludes with consideration of the general theoretical and managerial implications of our findings and directions for future research.

\section{Theoretical background}

\section{Defining AI}

We draw on mobile banking literature (Payne et al., 2018), technology acceptance model theory (Davis, 1989; Davis and Venkatesh, 1996) and diffusion of innovation theory (Rogers, 1995) to provide an overview of AI, its definition, and its context of use.

The full capabilities and limitations of AI in customer service are still being discovered, as researchers are just beginning to investigate consumers' responses to and preferences regarding AI and human customer service experiences (Van Esch et al., 2019). With AI reaching a critical threshold in terms of its implementation in customer service contexts, there is a pressing need to clarify its place in business, management, and marketing overall and to arrive at an accepted definition of it (Table 1). For this research, since we were interested in comparing customers' service preferences (AI vs. Human), we developed our own definition of AI in customer service and we understand it to be: A technology-enabled system for evaluating real-time service scenarios using data collected from digital and/or physical sources in order to provide personalised recommendations, alternatives, and solutions to customers' enquiries or problems, even very complex ones.

\section{AI in service encounters}

We draw on affordance-experimentation-actualisation theory (Strong et al., 2014; Keller et al., 2019) and service robots, customers, and service employees literature (Lu et al., 2020), to show the different types of AI-enabled service encounters and their interplay with the financial and banking sectors (Foroughi et al., 2019).

Ostrom et al. (2019) identified three types of AI-enabled service encounters: AI-supported, AI-augmented, and AI-performed. In AIsupported service encounters, frontline employees perform a service and directly interact with customers while relying on AI for assistance behind the scenes with decision-making or customisation of the service experience in real-time, an example being the use of AI by physicians to diagnose patients. In AI-augmented service encounters, AI interacts directly with customers or is used by frontline employees assisting them (as opposed to behind the scenes), augmenting the traditional encounter with enhanced information or innovative services, for example, real-time language translation. In AI-performed service encounters, AI takes the place of an employee, interacting directly with the customer to co-create and deliver the entire service experience; examples include the chatbots used in retailing and banking and such virtual assistants as Apple's Siri.

\section{AI in customer service}

We draw on customer engagement, consumption and firm performance literature (Ho et al., 2020), transactive relationship theory (Tanioka et al., 2019), and AI in service literature (Hui et al., 2001; Huang and Rust, 2018; Davenport and Ronanki, 2018) to show that as organisations experiment with new touch-points along the customer journey, they are looking to AI-enabled technologies to provide effective and engaging customer service (Bitner, 2001, 2017; Meuter et al., 2000). In particular, through online customer service, customers are able to contact organisations at their own convenience, a capability that creates value through time-saving and convenience, increases customer satisfaction, and enhances brand loyalty (Colwell et al., 2008; Negash et al., 2003).

With the advances in AI-enabled technology, many organisations are now providing online customer support through instant messaging platforms in what are called live chat systems (McLean and Wilson, 2016; Turel and Connelly, 2013; Van Esch and Black, 2019). In addition to its other advantages, this platform allows customers to seek service-related information from an organisation by means of web-based synchronous media interactions that are supported by human service employees engaging in two-way communication (Van Gog et al., 2011; Turel and Connelly, 2013). For customers, the most important elements of satisfaction in a service context are connection, response time, and the quality of the response (Cheong et al., 2008; Verhoef et al., 2009). The live chat customer service system facilitates consumers' decision-making with respect to searching, guidance, and assistance (Chattaraman et al., 2012).

Customers often over-estimate their wait time during their service experience, and they are especially sensitive to being compelled to wait online. Long online wait times, then, contribute to a negative service experience (McLean anad Osei-Frimpong, 2017; McLean and Wilson, 2016). Alternatively, when customers use a human-staffed customer service system, they must often endure queuing, connecting, and waiting for a response to resolve their problems (Vandenberghe et al., 2007). AI-enabled customer service systems, by contrast, can provide immediate responses around 


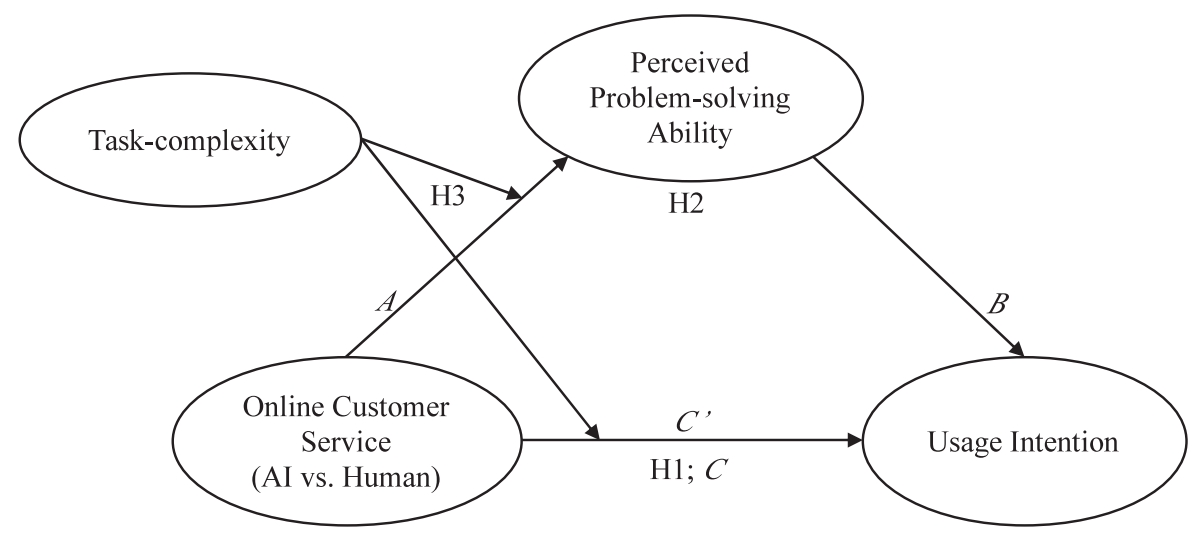

Fig. 1. Theoretical framework.

the clock to customers' problems (Van Esch and Mente, 2018). This advantage explains the implementation of AI customer service in the banking and retailing industries. For example, according to one study, nearly all (99.78\%) of the retailer Uniqlo's customer service was provided by AI, with nearly half $(48 \%)$ of customers who utilised the AI-enabled service also making a purchase (Morgan, 2019). Likewise, in the banking industry, 6,000 of the customers of China Trust Inc. use AI-enabled customer service daily to resolve $88 \%$ of interactions. Therefore, we propose our first hypothesis:

$\mathbf{H}_{\mathbf{1}}$ : AI customer service has a positive influence on usage intention.

The problem-solving capacity of AI customer service

We draw on problem solving with AI literature (Fox, 1990; Kirsh, 1991; Steels, 2007; Jarrahi, 2018) to understand that by exploiting such forms of $\mathrm{AI}$ as chatbots to replace human employees in a live system, companies can provide instant customer service without human time and labour constraints (Shankar, 2018). Chatbots utilise machine learning, deep learning, and natural language processing to solve problems (Huang and Rust, 2018; Kaplan and Haenlein, 2019; Ostrom et al., 2019). Machine learning can mimic the human brain and perform complex computing and decisionmaking tasks that produce the best possible solutions with little or no error (Kaplan and Haenlein, 2019).

Thanks to natural language processing, a chatbot can identify keywords in a customer's query and respond in kind with a coherent message, one often formulated by drawing on a sophisticated data base. Thanks to deep learning, AI can adjust and improve its responses every time it is used and can update and increase the size of the database from which it can select as a future resource (Kaplan and Haenlein, 2019; McCarthy, 2007). These features make a chatbot a powerful problem-solving tool for use in a customer service context (Klie, 2013; Ostrom et al., 2019; Xiao and Kumar, 2019). Therefore, we propose our second hypothesis:

$\mathbf{H}_{\mathbf{2}}$ : Perceived problem-solving ability mediates the relationship between AI customer service and usage intention.

Task complexity in customer service

We draw on task complexity literature (Byström and Järvelin, 1995; Campbell, 1988; Fan et al., 2018; Nemati et al., 2002;) to show that when customers interact with a customer service system, they experience information overload if they receive too much information at once (Xuet al., 2014). Wood (1986) introduced the concept of task complexity to describe the amount of information relevant to the performance of a given task. Task complexity has also been identified as the key factor in cognitive load, being a measure of the burden that carrying out a given task places on an individual's cognitive system (Kirschner et al., 2009; Klemz and Gruca, 2003; Van Gog et al., 2011). Consequently, when an individual processes information, his or her cognitive load is affected by task complexity, so that the simplicity of a task correlates negatively with its cognitive load (Sweller et al., 1998).

Task complexity can affect the knowledge, skills, and motivation needed for the performance of a task (Campbell, 1988; Hærem et al., 2015; Wood, 1986). Thus individuals invest more time and effort as task complexity increases and adjust their judgment, performance, and expectations accordingly (Xu, 2016; Lankton et al., 2010). Consequently, the high expectations in the high task complexity problems will lead to a potential disappointment towards AI ("AI should be smart" heuristic). Therefore, we could expect the opposite effects of AI could occur in high vs low complexity condition. In view of these arguments, we proposed the theoretical framework illustrated in Fig. 1 and the third hypothesis:

$\mathbf{H}_{\mathbf{3}}$ : Task complexity moderates the mediation effect of problem-solving ability on AI customer service and usage intention, resulting in moderated mediation.

Study 1

Design, participants, and procedure

Study 1 focused on the effects of various customer service systems (AI or Human). The 51 participants (male $=51 \%$, female $=49 \% ; M_{\text {age }}=26.04$, age-range $=17-57$ years) who participated in this field-based experiment were assigned randomly to one experimental condition, in a two (customer service: AI vs. Human) within-subject design for which usage intention served as the focal outcome (Rindfleisch et al., 2008; Young and Selto, 1993). The participants accessed the AI customer service and human customer service systems of Cathay United Bank, which is located in the Shinkuchan Commercial District in Kaohsiung, Taiwan, in order to ask three questions related to credit card use issues (see Appendix).

The order of the two customer service systems is to adopt a counter-balanced method to avoid the order effect. The results of the order effect for all items are insignificant $(p>0.1)$. All of the items were measured using a seven-point Likert scale with values ranging from 1 (not at all) to 7 (very much). Usage intention $(\alpha=0.95)$ was adapted from Fishbein and Ajzen (1977; Table 2).

\section{Results and discussion}

Manipulation check. A three-item scale was adopted to examine the manipulation for the comparison of the AI and human 
Table 2

\begin{tabular}{|c|c|c|c|}
\hline Variables & $\begin{array}{l}\text { Factor loading } \\
\text { Study } 1\end{array}$ & Study 2 & Study 3 \\
\hline \multicolumn{4}{|l|}{ Online customer service (AI vs. Human) } \\
\hline After asking my question, this $\mathrm{AI} / \mathrm{Human}$ customer service can respond immediately. & 0.82 & 0.79 & 0.87 \\
\hline After asking my question, I can get a solution immediately from the AI/Human customer service. & 0.86 & 0.93 & 0.91 \\
\hline $\begin{array}{l}\text { When answering my question, the } \mathrm{AI} / \text { Human customer service response is logical. } \\
\text { Problem-solving ability (Beldad et al., 2016) }\end{array}$ & 0.74 & 0.79 & 0.80 \\
\hline This customer service system fully understands my problems. & & 0.88 & 0.86 \\
\hline This customer service system can respond to the questions I ask. & & 0.92 & 0.86 \\
\hline This customer service system can provide useful answers for me. & & 0.94 & 0.92 \\
\hline $\begin{array}{l}\text { Overall, this customer service system is qualified and capable. } \\
\text { Usage intention (Fishbein, and Ajzen, 1977) }\end{array}$ & & 0.91 & 0.91 \\
\hline I am interested in using this customer service system. & 0.86 & 0.79 & 0.70 \\
\hline This customer service system increases my willingness to use it. & 0.94 & 0.95 & 0.86 \\
\hline I would recommend this customer service system to others to use for consultation. & 0.97 & 0.90 & 0.91 \\
\hline $\begin{array}{l}\text { I will use this AI/Human customer service system for consultation. } \\
\text { Task complexity (Gupta et al., 2013) }\end{array}$ & 0.84 & 0.91 & 0.88 \\
\hline I think that this is a complicated question. & & & 0.95 \\
\hline I think that this question is difficult to understand. & & & 0.97 \\
\hline I need to think through the answer from customer service to understand it fully. & & & 0.95 \\
\hline
\end{tabular}

customer service conditions $(\alpha=0.85)$. The participants in the AI condition rated the sufficiency of customer information in the scenarios significantly higher than those in the human condition $\left(M_{\mathrm{AI}}=6.50, S D=0.64\right.$ vs. $M_{\mathrm{Human}}=4.13, S D=1.44, t(50)=72.46$, $p<.001)$.

Results. We conducted an ANOVA of usage intention with customer service as the independent variable and age, gender, and education as covariates. Usage intention was greater with AI than with human customer service $\left(M_{\mathrm{AI}}=5.97, S D=0.92\right.$ vs. $\left.M_{\text {Human }}=3.97, S D=1.72, t(50)=8.03, p<0.001\right)$. Therefore, $\mathrm{H}_{1}$ was supported.

\section{Study 2}

\section{Design, participants, and procedure}

Study 2 replicated Study 1 but included another objective, namely to test whether problem-solving ability mediates the relationship between customer service (AI vs. Human) and usage intention. The 181 participants (male $=43.6 \%$, female $56.7 \%$; $M_{\mathrm{age}}=30.68$, age range $=20-53$ years) in this field-based experiment were randomly assigned to one experimental condition, in a two (customer service: AI vs. Human) within-subject design in which usage intention served as the focal outcome. The participants asked the same three questions regarding credit card issues as those asked in Study 1 (Appendix A). The order of the two customer service systems is to adopt a counter-balanced method to avoid the order effect. The results of the order effect for all items are insignificant $(p>0.1)$. The measurement items were usage intention $(\alpha=0.94)$ and problem-solving ability $(\alpha=0.95)$ (Beldad et al., 2016).

We performed a confirmatory factor analysis in order to assess the psychometric adequacy of the constructs (Table 2). All of the item loadings of problem-solving and usage intention proved to be significant $(p<0.01)$ and therefore supported the convergent validity of the experiment. Further, the measurement model provided good fit with the data $(\chi 2 / \mathrm{df}=1.66, \mathrm{CFI}=0.99$, TLI $=0.99$, RMSEA $=0.06$ ). The discriminant validity of the constructs indicated that the average variance of each construct extracted was greater than its squared correlation with any other construct in the model. In other words, the measures showed that neither discriminant validity nor multicollinearity had an effect on the model (Grewal et al., 2004).

\section{Results and discussion}

Manipulation. The manipulation check $(\alpha=0.87)$ functioned as intended $\left(M_{\mathrm{AI}}=6.20, S D=0.68\right.$ vs. $M_{\text {Human }}=4.3 ; S D=1.58$, $t(180)=122.02, p<.001)$. The participants in the AI condition rated the sufficiency of the customer information in the scenarios significantly higher than the participants in the human condition.

Results. An ANOVA of usage intention with customer service as the independent variable showed a significant main effect $\left(M_{\mathrm{AI}}=5.12, S D=1.17\right.$ vs. $M_{\text {Human }}=4.69, S D=1.55, t(180)=2.17$, $p<0.05)$. Thus, in Study 2, AI customer service led to greater usage intention than human customer service. There were no significant differences associated with age, gender, or education $(p>10)$. These results, like those from Study 1 , support $\mathrm{H}_{1}$.

To test the causal mechanism of problem-solving ability, we used Hayes PROCESS Model 4 (Hayes, 2013, 2017). The total effect (Path $C$ ) was significant and positive with regard to usage intention $\left(\beta=.597, t(179)=9.37, p<0.001, \mathrm{Cl}_{95 \%}: 0.47,0.72\right)$ and problemsolving (Path A, $\beta=0.657, t(179)=11.34, p<.001, \mathrm{Cl}_{95 \%}$ : 0.54 , 0.77). The mediating effect (Path $\mathrm{AB}$ ) also remained significant $(\beta$ $=0.20, t(178)=2.69, p<0.05, \mathrm{Cl}_{95 \%}: 0.05,0.35$; Sobel $\mathrm{z}=6.66, p$ $<0.001$ ). The results of Study 2 thus support H2: problem-solving partially mediated the effect of customer service (for AI vs. human) on usage intention.

\section{Study 3}

\section{Design, participants, and procedure}

Study 3 replicated Study 2 and added another objective, namely to compare task complexity (high and low) as a boundary condition of the mediated model. The 100 participants (male $=51 \%$, female $=49 \% ; M_{\text {age }}=26.64$, age-range $=16-55$ years $)$ in the fieldbased experiment were randomly assigned to a 2 (customer service: AI vs. Human) $\times 2$ (task complexity: High vs. Low) mixed factorial design for which usage intention served as the focal outcome. Replicating studies 1 and 2, the order of the two customer service systems adopted a counter-balanced method. The results of the order effect for all items are insignificant $(p>0.1)$. The measurement items included usage intention $(\alpha=0.91)$, problemsolving $(\alpha=0.94)$, and task complexity ( $\alpha=0.90$; Gupta et al., 2013; Appendix B).

Confirmatory factor analysis indicated that all of the item loadings of online customer service and usage intention were significant $(p<.01)$, thereby supporting convergent validity, and that 


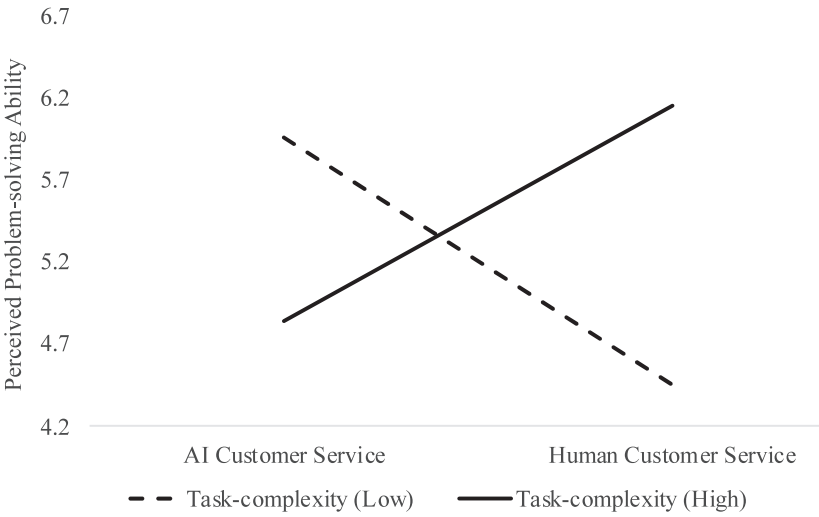

Fig. 2. Perceived problem-solving ability as a function of customer service (AI vs. Human) and task complexity (Study 3).

the measurement model provided good fit with the data for task complexity $(\chi 2 / \mathrm{df}=0.02, \mathrm{CFI}=1.00, \mathrm{TLI}=1.00$, RMSEA $=0.002)$, problem-solving, and usage intention $(\chi 2 / \mathrm{df}=1.10$, CFI $=0.99$, TLI $=0.99$, RMSEA $=0.03$ ). Again, neither discriminant validity nor multi-collinearity affected the model.

\section{Results and discussion}

Manipulation. The manipulation check $(\alpha=0.90)$ functioned as intended $\left(M_{\mathrm{AI}}=6.08, S D=0.91\right.$ vs. $M_{\text {Human }}=3.94, S D=1.55$; $t(99)=25.50, p<0.001)$. The participants in the AI condition rated the sufficiency of customer information in the scenarios significantly higher than that in the human condition. The task complexity (TC; high vs. low) manipulation check functioned as intended: participants in the high-TC condition reported greater task difficulty than those in the low-TC condition (AI condition: $M_{\text {High }}=5.71, S D=1.02$, vs. $M_{\text {Low }}=2.37, S D=1.08, t(98)=-$ $15.90, p<0.001$; human condition: $M_{\mathrm{High}}=4.28, S D=1.26$ vs. $\left.M_{\text {Low }}=2.23, S D=1.30, t(98)=-8.01, p<0.001\right)$.

Results. We conducted a two-way repeated ANCOVA of problem-solving with customer service as the independent variable, task complexity as the moderator, and age, gender, and education as the covariates. We found a significant main effect of customer service on problem-solving $\left(M_{\mathrm{AI}}=5.21, S D=1.40\right.$ vs. $M_{\text {Human }}=5.50, S D=1.44, F(1,95)=4.32$, partial $\left.\eta 2=.04, p<0.05\right)$, but the effect of task complexity on problem-solving was not significant $\left(M_{\text {High }}=5.31, S D=0.13\right.$ vs. $M_{\text {Low }}=5.40, S D=0.13, F(1$, $95)=0.26$, partial $\eta 2=.00, p>0.1)$. The participants in the AI condition found the problem-solving more effective than those in the human customer service condition. We found significant interaction effects of customer service (for AI compared with human) and task complexity on problem-solving ability $(F(1,95)=59.59$, partial $\eta 2=0.38, p<0.01)$. For the low task complexity condition, problem-solving ability was greater for AI than for human customer service. For the high-TC condition, problem-solving ability was higher in the human than AI customer service. Once more, no significant differences were associated with age, gender, or education ( $p>0.10$; Fig. 2).

Next, we conducted a two-way repeated ANCOVA of usage intention with customer service as the independent variable and task complexity as the moderator and with age, gender, and education as covariates. The results showed a significant main effect of customer service on usage intention $\left(M_{\mathrm{AI}}=5.00, S D=1.38\right.$ vs. $\left.M_{\text {Human }}=4.36, S D=1.34, F(1,95)=4.34, p<0.001\right)$, but the effect of task complexity on usage intention was not significant. The participants in the AI customer service condition indicated greater usage intention than those in the human customer service condition. There was a significant interaction effect between customer service and task complexity on usage intention $(F(1,95)=81.10$, partial

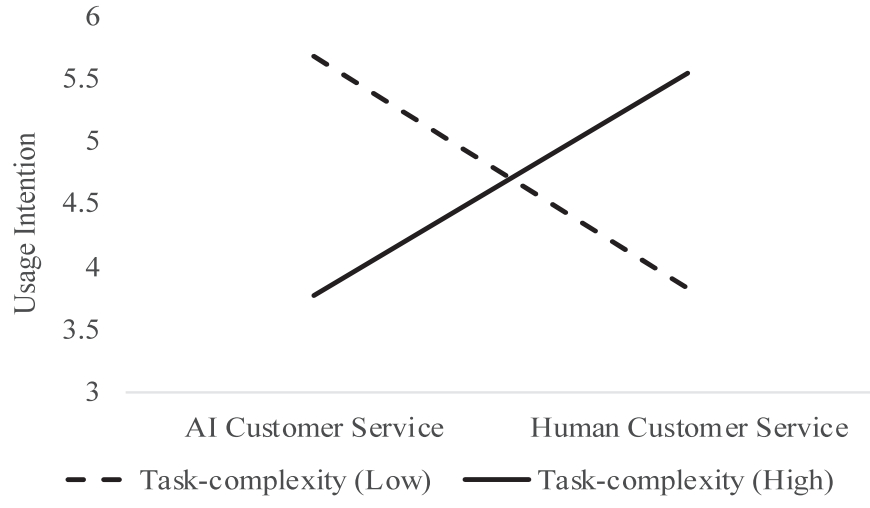

Fig. 3. Usage intention as a function of customer service (AI vs. Human) and task complexity (Study 3).

Table 3

Regression results (Study 3).

\begin{tabular}{lll}
\hline Independent variable & $\begin{array}{l}\text { Online customer service } \\
\text { Problem-solving ability }\end{array}$ & Usage intention \\
\hline Constant & $2.99^{* * *}$ & $1.29^{* *}$ \\
Online Customer Service (CS) & $0.49^{* * *}$ & 0.16 \\
Task complexity (TC) & -0.53 & 0.04 \\
CS $\times$ TC & 0.07 & -0.02 \\
Problem-solving Ability & - & $0.50^{* * *}$ \\
$R^{2}$ & 0.30 & 0.36 \\
$F$ & $13.50^{* * *}$ & $13.49^{* * *}$ \\
$d f$ & 96 & 95 \\
\hline
\end{tabular}

Note. Unstandardised coefficients are shown; ${ }^{* * *} p<.001,{ }^{* *} p<.05$.

$\eta 2=0.46, p<0.001)$. For the low task complexity condition, usage intention was greater for AI customer service than for human customer service. For the high-TC condition, the usage intention was grater for human customer service (Fig. 3). Lastly, we conducted a mediated moderation analysis (Model 8; Hayes, 2013) to determine whether problem-solving mediated the interaction effect of online customer service and task complexity on usage intention, thereby resulting in mediated moderation.

The results showed a significant effect of problem-solving on usage intention $\left(\beta=0.497, t(95)=5.14, p<0.001 ; \mathrm{Cl}_{95 \%}\right.$ : 0.305, 0.689 ). The interaction of customer service and task complexity on usage intention, was not significant, nor was the effect of task complexity on usage intention $(\beta=0.04, t(95)=5.08$, $p>0.1 ; \mathrm{Cl}_{95 \%}$ : $\left.-1.55,1.63\right)$. We conducted a bootstrapping analysis to test the conditional effect (indirect, using 5,000 samples; Hayes, 2013, 2018) that generated a 95\% confidence interval; therefore, we were able to determine mediation because zero was not bracketed (Preacher and Hayes, 2008; Zhao et al., 2010). The results showed a significant indirect effect for customer service on usage intention for both the low-TC ( $\beta=0.242, \mathrm{Cl}_{95 \%}$ : $1.11,0.42$ ) and high-TC $\left(\beta=0.278, \mathrm{Cl}_{95 \%}: 0.18,0.40\right)$ conditions. Therefore, the index of moderated mediation was significant and $\mathrm{H} 3$ is supported (Table 3).

\section{General discussion}

Contributions and Implications of the Findings

In this research, we compared the effect of AI customer service with that of human customer service on customer usage intention. We found that customers perceived that AI had greater problemsolving capacity and displayed greater intention to use that form of customer service for low-complexity tasks. Consumers perceived that human customer service had greater problem-solving ability and showed greater intention to use human customer service for high-complexity tasks. Our three field-based experiments con- 
ducted at Cathay United Bank in Taiwan thus provided converging evidence for our theoretical framework.

\section{Theoretical contributions}

We contribute to the literature on AI customer service by revealing fresh insights into the role of problem-solving ability as a causal mechanism promoting the effectiveness of AI customer service and usage intention. Though AI customer service systems have become popular, little effort has been made to compare their effectiveness with that of traditional online human customer service systems. Our field studies corroborate prior research by suggesting that customers prefer live-chat human customer service systems for high-complexity tasks (Klie, 2013) but prefer AI customer service systems for low-complexity tasks (Kirkpatrick, 2017).

Moreover, our findings contribute to the literature on technology-based customer service by demonstrating that task complexity is an important boundary condition for the effectiveness of AI customer service. For the participants in our study, task complexity affected usage intention regarding an online customer service system, again corroborating prior research, in this case by showing that cognitive capacity can be influenced by the amount of information that needs to be processed during a customer service interaction (Kamis et al., 2008; Xu et al., 2014). Our research, then, suggests that, AI customer service systems are perceived to have a greater problem-solving ability and increase usage intention for low-complexity tasks but that, human customer service systems are perceived to have a greater problem-solving ability and increase usage intention for high-complexity tasks.

\section{Practical implications}

An earlier study conducted in Taiwan (Muro and Andes, 2015) estimated the cost of providing human customer service at USD \$10.72 per interaction, compared with just USD\$2.10 for an AI customer service response. Under such conditions, organisations can reduce their costs by substituting human customer service with AI customer service. It is not the case, however, that an AI customer service agent, such as a chatbot, reduces the overall need for human service employees; rather, these technologies are changing the ways in which service employees work. In the case of online customer service, workers can focus their efforts on solving difficult and complex problems while leaving simple routine tasks to AI.

From the perspective of financial service providers, such as banks, the primary consideration is leveraging AI customer service systems in order to achieve cost savings and provide a better service experience for their customers. Thus, for example, when a customer contacts an online customer service system, a pop-up window may appear that presents two or three simple questions intended to assess the complexity of the query; then, based on this assessment, the customer can be directed either to the AI or the human customer service option. In such ways, banks can reduce the time that their customers need to devote to service issues and their own operational costs while improving the overall customer service experience (Black and Van Esch, 2020).

\section{Directions for future research}

Our work has revealed several paths for future research. First, though we have presented convincing evidence that problemsolving ability plays a mediating role in the preference for either AI or Human customer service, in usage intention, and in task complexity as a boundary condition, the robustness of our findings could be assessed by exploring the significance of problem-solving ability and task complexity in other online customer service contexts across a range of different industries, countries, and consumer demographics. Another line of enquiry could involve consideration of further factors in relation to AI, such as customers' technology readiness and the influence of previous experiences with the technology on service usage intentions. Customers' perceptions of task complexity also merit closer examination, especially their criteria for distinguishing high-complexity tasks from lowcomplexity ones and for assessing problem-solving ability, since these appear to be the key factors in the preference for either AI or Human customer service. Such research could serve as the basis for a typology of comparisons and for assessing how best to exploit $\mathrm{AI}$ in customer service contexts across a range of task complexities. 


\section{Appendix A. Studies 1 and 2}

Step 1: The interviewer explained the experimental situation to the participants.

Step 2: The participants asked the customer service systems (AI vs. Human) three questions using the dialog box:

Q1: I am going to go abroad next month; what should I do if I accidentally lose my credit card?

Q2: What are the requirements when applying for a new credit card?

Q3: Is there a discount when I use the credit card in a restaurant?

The below screenshots show one of the dialogs regarding Q2:

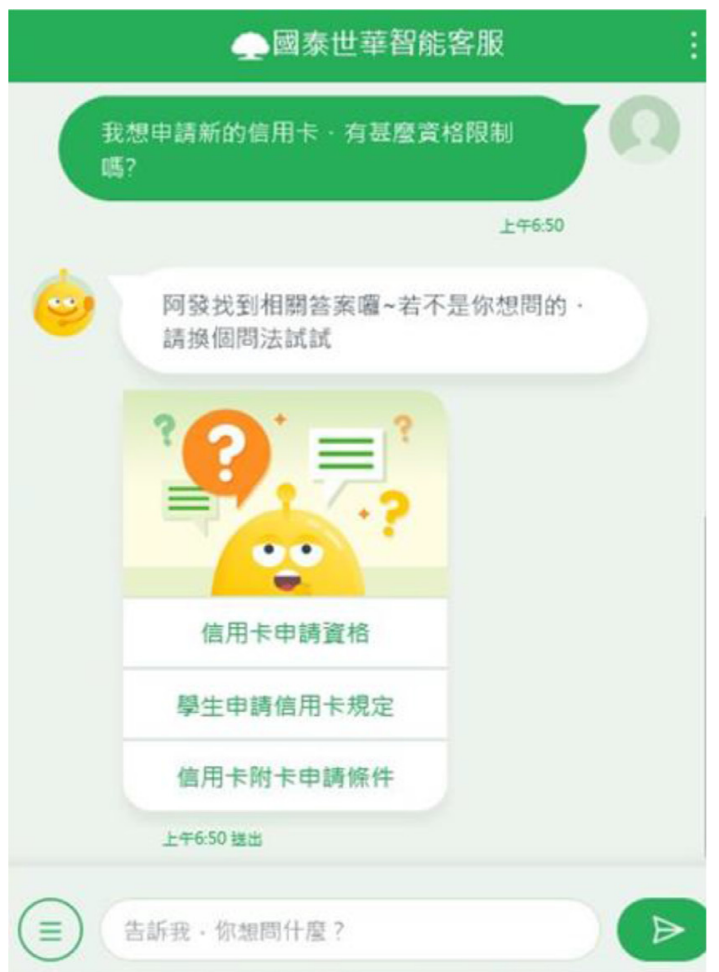

AI customer service

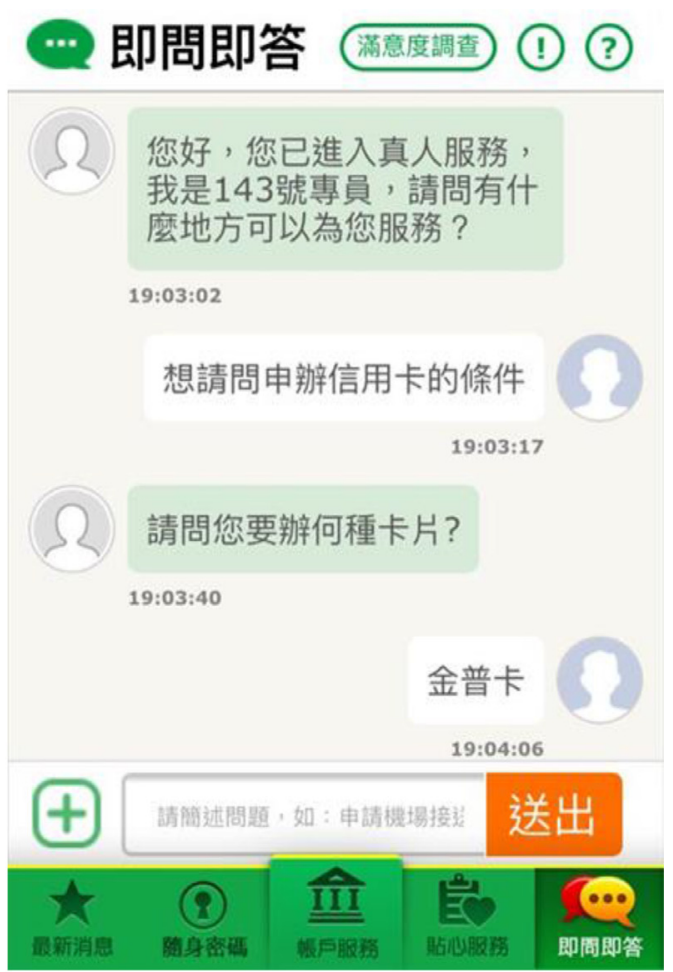

Human customer service 
AI customer service Human customer service

The translation of the dialog in the above screenshots:

AI customer service

Customer: What are the requirements when applying for a new credit card?

AI: Ah-Fa found the relevant answer for you! If the answer is not what you need, please try to ask me another question. Please choose the following options: Eligibility for credit card applications; Credit card requirements for students; Requirements for credit card sub-cards application.

\section{Human customer service}

Human agent: Hello, I am customer service agent number 143. How can I help you?

Customer: What are the requirements for applying for a new credit card?

Human agent: What kind of credit card do you want to apply for?

Customer: Regular credit card.

\section{Appendix B. Study 3}

Step 1: The interviewer explained the experimental situation to the participants as follows:

You are going abroad next month and are worried about losing your credit card; therefore, you try to ask some questions in advance using the customer service system.

Step 2: The participants asked the customer service systems (AI vs. Human) three questions comparing high and low task complexity inquiries using the dialogue box.

Step 3a: (High task complexity questions):

Q1: How do I calculate the minimum amount that I need to pay on my credit card each month?

Q2: How do I get credit card cash advance when I am abroad?

Q3: When using a credit card abroad, what are the additional fees?

The below screenshots show the dialog regarding Q2:

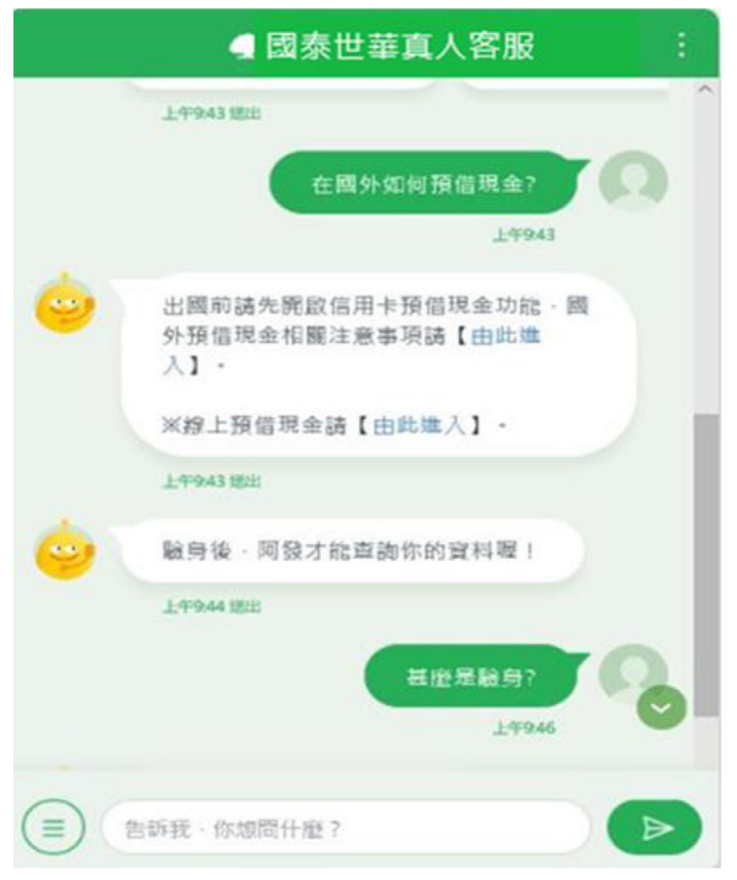

AI customer service

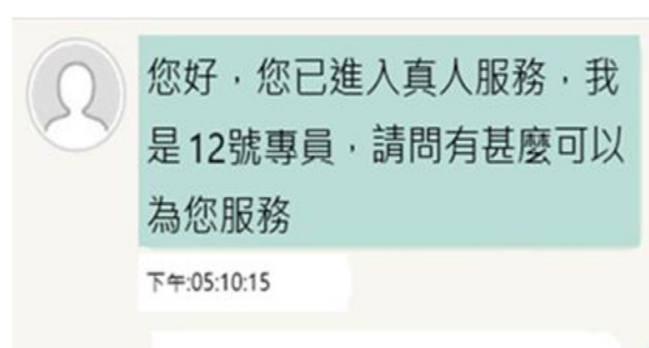

在國外如何預借現金?

下午:05:10:35

您好，若申請時有設定預借現金功

能，就可以馬上使用。若沒有設

定，我將為您服務。

下午:05:11:01

申請時沒有設定，請管我現在設定

下午:05:11:35

\section{Human customer service}


AI customer service Human customer service

The translation of the dialog in the above screenshots:

AI customer service: High task complexity

Customer: How do I get a credit card cash advance when I am abroad?

AI: Before going abroad, please activate your credit card cash advance function. Please choose the following option: Guideline for cash advances abroad [please enter here]; apply cash advance [please enter here].

AI: After verification, Ah-fa can check your information.

Customer: What do you mean by verification?

Human customer service: High task complexity

Human agent: Hello, I am a customer service agent number 12. How can I help you?

Customer: How do I get a credit card cash advance when I am abroad?

Human agent: If you already set up the function for a cash advance when you applied for your credit card, you can use the function immediately. Otherwise, I will help you to set up this function.

Customer: I didn't set up this function when I applied for my credit card, please help me set it up now.

Step 3b: (Low task complexity questions):

Q1: What are the requirements for applying for a new credit card? What information should I include?

Q2: What should I do when my credit card expires?

Q3: How long does it take to apply for a new credit card?

The below screenshots show the dialog regarding Q2:

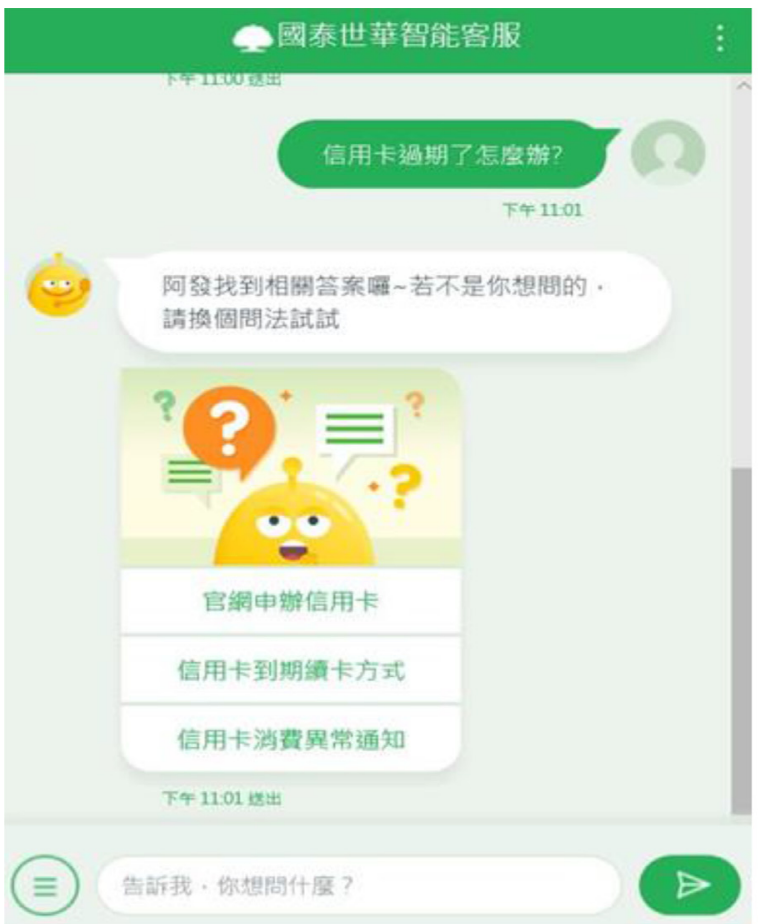

AI service

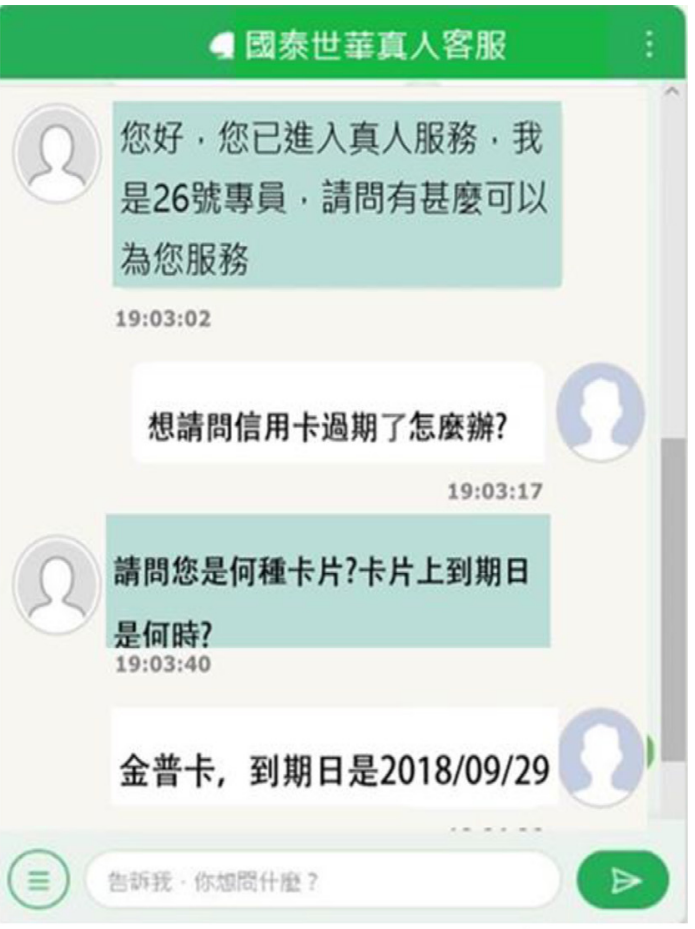

Human customer service 
AI service Human customer service

The translation of the dialog in the above screenshots:

\section{AI customer service: Low task complexity}

Customer: What should I do when my credit card expires?

AI: Ah-Fa has found the relevant answer for you! If the answer is not what you need, please try to ask me another question. Please choose the following options:

Apply for a credit card online; Credit card renewal; Notification for abnormal expenses.

\section{Human customer service: Low task complexity}

Human agent: Hello, I am a customer service agent number 26 . How can I help you?

Customer: What should I do when my credit card expires?

Human agent: What kind of credit card do you have? What is the expiry date?

Customer: Regular card. The expiry date is 29/09/2018.

\section{References}

Beldad, A., Hegner, S., Hoppen, J., 2016. The effect of virtual sales agent (VSA) gender-product gender congruence on product advice credibility, trust in VSA and online vendor, and purchase intention. Comput. Hum. Behav. 60, 62-72.

Bitner, M.J., 2001. Service and technology: opportunities and paradoxes. Manag. Serv. Qual.: Int. J. 11 (6), 375-379.

Bitner, M.J., 2017. Service Research: Rigor, Relevance, and Community. SAGE Publications, Los Angeles, CA.

Black, S.J., Van Esch, P., 2020. AI-enabled recruiting: what is it and how should a manager use it? Bus. Horiz. 63 (2), 215-226.

Byström, K., Järvelin, K., 1995. Task complexity affects information seeking and use. Inf. Process. Manag. 31 (2), 191-213.

Campbell, D.J., 1988. Task complexity: a review and analysis. Acad. Manag. Rev. 13 (1), 40-52.

Chattaraman, V., Kwon, W.-S., Gilbert, J.E., 2012. Virtual agents in retail web sites: benefits of simulated social interaction for older users. Comput. Hum. Behav. 28 (6), 2055-2066.

Cheong, K., Kim, J., So, S., 2008. A study of strategic call center management: relationship between key performance indicators and customer satisfaction. Eur. J. Soc. Sci. 6 (2), 268-276.

Colwell, S.R., Aung, M., Kanetkar, V., Holden, A.L., 2008. Toward a measure of service convenience: multiple-item scale development and empirical test. J. Serv. Mark. 22 (2), 160-169.

Davenport, T.H., Ronanki, R., 2018. Artificial intelligence for the real world. Harv. Bus. Rev. 96 (1), 108-116.

Davis, F.D., 1989. Perceived usefulness, perceived ease of use, and user acceptance of information technology. MIS Q. 13 (3), 319-340.

Davis, F.D., Venkatesh, V., 1996. A critical assessment of potential measurement biases in the technology acceptance model: three experiments. Int. J. Hum. Comput. Stud. 45 (1), 19-45.

Dobrev, D., 2005. Formal definition of artificial intelligence. Int. J. Inf. Theor. Appl. $12,277-285$.

Dreyfus, H.L., Dreyfus, S.E., 1989. Why Computers May Never Think Like People. MIT Press, pp. 125-143.

Fan, W., Liu, J., Zhu, S., Pardalos, P.M., 2018. Investigating the impacting factors for the healthcare professionals to adopt artificial intelligence-based medical diagnosis support system (AIMDSS). Ann. Oper. Res. 1-26.

Fishbein, M., \& Ajzen, I. (1977). Belief, Attitude, Intention, and Behavior: An Introduction to Theory and Research.

Foroughi, B., Iranmanesh, M., Hyun, S.S., 2019. Understanding the determinants of mobile banking continuance usage intention. J. Enterp. Inf. Manag. 32 (6), 1015-1033.

Fox, M.S., 1990. AI and expert system myths, legends, and facts. IEEE Intell. Syst. (1) 8-20.

Grewal, R., Cote, J.A., Baumgartner, H., 2004. Multicollinearity and measurement error in structural equation models: Implications for theory testing. Mark. Sci. 23 (4), 519-529.

Gupta, A., Li, H., Sharda, R., 2013. Should I send this message? Understanding the impact of interruptions, social hierarchy and perceived task complexity on user performance and perceived workload. Decis. Support Syst. 55 (1), 135-145.

Hærem, T., Pentland, B.T., Miller, K.D., 2015. Task complexity: extending a core concept. Acad. Manage. Rev. 40 (3), 446-460.

Hayes, A.F., 2013. Introduction to Mediation, Moderation, and Conditional Process Analysis. A Regression-Based Approach. Guilford Press, New York.

Hayes, A.F., 2018. Partial, conditional, and moderated moderated mediation: quantification, inference, and interpretation. Commun. Monogr. 85 (1), 4-40.
Hayes, A.F., Montoya, A.K., Rockwood, N.J., 2017. The analysis of mechanisms and their contingencies: process versus structural equation modeling. Australas. Mark. J. 25 (1), 76-81.

Ho, M.H.W., Chung, H.F., Kingshott, R., Chiu, C.C., 2020. Customer engagement, consumption and firm performance in a multi-actor service eco-system: the moderating role of resource integration. J. Bus. Res. doi:10.1016/j.jbusres.2020.02.008.

Huang, M.-H., Rust, R.T., 2018. Artificial intelligence in service. J. Serv. Res. 21 (2), $155-172$.

Hui, S.C., Fong, A.C.M., Jha, G., 2001. A web-based intelligent fault diagnosis system for customer service support. Eng. Appl. Artif. Intell. 14 (4), 537-548.

Jarrahi, M.H., 2018. Artificial intelligence and the future of work: human-AI symbiosis in organizational decision making. Bus. Horiz. 61 (4), 577-586.

Kamis, A., Koufaris, M., Stern, T., 2008. Using an attribute-based decision support system for user-customized products online: an experimental investigation. MIS Q. 32 (1), 159-177.

Kaplan, A., Haenlein, M., 2019. Siri, Siri, in my hand: who's the fairest in the land? On the interpretations, illustrations, and implications of artificial intelligence. Bus. Horiz. 62 (1), 15-25.

Keller, R., Stohr, A., Fridgen, G., Lockl, J., \& Rieger, A. (2019). AffordanceExperimentation-Actualization Theory in Artificial Intelligence Research - A Predictive Maintenance Story.

Kirkpatrick, K., 2017. AI in contact centers. Commun. ACM 60 (8), 18-19.

Kirschner, F., Paas, F., Kirschner, P.A., 2009. Individual and group-based learning from complex cognitive tasks: effects on retention and transfer efficiency. Comput. Hum. Behav. 25 (2), 306-314.

Kirsh, D., 1991. Foundations of AI: the big issues. Artif. Intell. 47 (1-3), 3-30.

Klemz, B.R., Gruca, T.S., 2003. Dueling or the battle royale? The impact of task complexity on the evaluation of entry threat. Psychol. Mark. 20 (11), 999-1016.

Klie, L., 2013. Should your company abandon phone support. CRM Mag. 17 (4), 24-27.

Lankton, N.K., Wilson, E.V., Mao, E., 2010. Antecedents and determinants of information technology habit. Inf. Manag. 47 (5-6), 300-307.

Lu, V.N., Wirtz, J., Kunz, W., Paluch, S., Gruber, T., Martins, A., Patterson, P., 2020. Service robots, customers, and service employees: what can we learn from the academic literature and where are the gaps? J. Serv. Theory Pract. doi:10.1108/ JSTP-04-2019-0088.

McLean, G., Osei-Frimpong, K., 2017. Examining satisfaction with the experience during a live chat service encounter-implications for website providers. Comput. Hum. Behav. 76, 494-508.

McCarthy, J. (2007). What is artificial intelligence?

McLean, G., Wilson, A., 2016. Evolving the online customer experience: is there a role for online customer support? Comput. Hum. Behav. 60, 602-610.

Meuter, M.L., Ostrom, A.L., Roundtree, R.I., Bitner, M.J., 2000. Self-service technologies: understanding customer satisfaction with technology-based service encounters. J. Mark. 64 (3), 50-64.

Morgan, B. (2019). The 20 Best Examples of Using Artificial Intelligence for Retail Experiences. Forbes. Retrieved from https://www.forbes.com/sites blakemorgan/2019/03/04/the-20-best-examples-of-using-artificial-intelligencefor-retail-experiences/\#65f08e304466

Muro, M., Andes, S., 2015. Robots seem to be improving productivity, not costing jobs. Harv. Bus. Rev. https://hbr.org/2015/06/robots-seem-to-beimprovingproductivity-not-costing-jobs.

Negash, S., Ryan, T., Igbaria, M., 2003. Quality and effectiveness in web-based customer support systems. Inf. Manag. 40 (8), 757-768.

Nemati, H.R., Steiger, D.M., Iyer, L.S., Herschel, R.T., 2002. Knowledge warehouse: an architectural integration of knowledge management, decision support, artificial intelligence and data warehousing. Decis. Support Syst. 33 (2), 143-161.

Ostrom, A.L., Fotheringham, D., Bitner, M.J., 2019. Customer acceptance of AI in service encounters: understanding antecedents and consequences. In: Handbook of Service Science, Volume II. Springer, pp. 77-103.

Payne, E.M., Peltier, J.W., Barger, V.A., 2018. Mobile banking and AI-enabled mobile banking. J. Res. Interact. Mark..

Preacher, K.J., Hayes, A.F., 2008. Asymptotic and resampling strategies for assessing and comparing indirect effects in multiple mediator models. Behav. Res. Methods 40 (3), 879-891.

Rindfleisch, A., Malter, A.J., Ganesan, S., Moorman, C., 2008. Cross-sectional versus longitudinal survey research: concepts, findings, and guidelines. J. Mark. Res. 45 (3), 261-279.

Rogers, E.M., 1995. Diffusion of Innovations. Free Press, New York, NY.

Rust, R.T., 2019. The future of marketing. Int. J. Res. Mark. doi:10.1016/j.ijresmar: 2019.08.002, Retrieved from.

Shankar, V., 2018. How Artificial Intelligence (AI) is Reshaping Retailing. Elsevier, New York, NY.

Steels, L., 2007. Fifty years of AI: from symbols to embodiment-and back. In: 50 Years of Artificial Intelligence. Springer, Berlin, Heidelberg, pp. 18-28.

Strong, D.M., Johnson, S.A., Tulu, B., Trudel, J., Volkoff, O., Pelletier, L.R., Bar-On, I., Garber, L., 2014. A theory of organization-EHR affordance actualization. J. Assoc. Inf. Syst. 15 (2), 53-85.

Sweller, J., Van Merrienboer, J.J., Paas, F.G., 1998. Cognitive architecture and instructional design. Educ. Psychol. Rev. 10 (3), 251-296.

Syam, N., Sharma, A., 2018. Waiting for a sales renaissance in the fourth industrial revolution: machine learning and artificial intelligence in sales research and practice. Ind. Mark. Manag. 69, 135-146. 
Tanioka, T., Yasuhara, Y., Dino, M.J.S., Kai, Y., Locsin, R.C., Schoenhofer, S.O., 2019. Disruptive engagements with technologies, robotics, and caring: advancing the transactive relationship theory of nursing. Nurs. Adm. Q. 43 (4), 313-321.

Tegmark, M., 2017. Life 3.0: Being Human in the Age of Artificial Intelligence. Knopf, New York, NY.

Turel, O., Connelly, C.E., 2013. Too busy to help: antecedents and outcomes of interactional justice in web-based service encounters. Int. J. Inf. Manag. 33 (4), 674-683.

Van Doorn, J., Mende, M., Noble, S.M., Hulland, J., Ostrom, A.L., Grewal, D., Petersen, J.A., 2017. Domo arigato Mr. Roboto: emergence of automated social presence in organizational frontlines and customers' service experiences. J. Serv. Res. 20 (1), 43-58.

Van Gog, T., Kester, L., Paas, F., 2011. Effects of concurrent monitoring on cognitive load and performance as a function of task complexity. Appl. Cogn. Psychol. 25 (4), 584-587.

Vandenberghe, C., Bentein, K., Michon, R., Chebat, J.-C., Tremblay, M., Fils, J.-F., 2007. An examination of the role of perceived support and employee commitment in employee-customer encounters. J. Appl. Psychol. 92 (4), 1177.

Van Esch, P., Black, S.J., 2019. Factors that influence new generation candidates to engage with and complete digital, Al-enabled recruiting. Bus. Horiz. 62 (6), 729-739.

Van Esch, P., Black, Ferolie, S.J., 2019. Marketing AI recruitment: the next phase in job application and selection. Comput. Hum. Behav. 90, 215-222.
Van Esch, P., Mente, M., 2018. Marketing video-enabled social media as part of your e-recruitment strategy: stop trying to be trendy. J. Retail. Consum. Serv. 44, 266-273.

Verhoef, P.C., Lemon, K.N., Parasuraman, A., Roggeveen, A., Tsiros, M. Schlesinger, L.A., 2009. Customer experience creation: determinants, dynamics and management strategies. J. Retail. 85 (1), 31-41.

Wirtz, J., Patterson, P.G., Kunz, W.H., Gruber, T., Lu, V.N., Paluch, S., Martins, A., 2018 Brave new world: service robots in the frontline. J. Serv. Manag. 29 (5), 907-931.

Wood, R.E., 1986. Task complexity: definition of the construct. Organ. Behav. Hum. Decis. Process. 37 (1), 60-82.

Xiao, L., Kumar, V., 2019. Robotics for customer service: a useful complement or an ultimate substitute? J. Serv. Res. doi:10.1177/1094670519878881.

Xu, J., Benbasat, I., Cenfetelli, R.T., 2014. Research note: the influences of online service technologies and task complexity on efficiency and personalization. Inf. Syst. Res. 25 (2), 420-436.

Xu, J.D., 2016. Retaining customers by utilizing technology-facilitated chat: mitigating website anxiety and task complexity. Inf. Manag. 53 (5), 554-569.

Young, S.M., Selto, F.H., 1993. Explaining cross-sectional workgroup performance differences in a JIT facility: a critical appraisal of a field-based study. J. Manag. Account. Res. 5, 300

Zhao, X., Lynch Jr, J.G., Chen, Q., 2010. Reconsidering Baron and Kenny: myths and truths about mediation analysis. J. Consum. Res. 37 (2), 197-206. 